\title{
Literature Review Analisis Faktor Keberhasilan Implementasi Sistem Informasi Manajemen Rumah Sakit Dengan Metode HOT-FIT
}

\author{
Literature Review Analysis of Implementation Success Factors \\ Hospital Management Information System Using HOT-FIT Method
}

\author{
Maisaroh Roaini ${ }^{1}$, Rohmadi $^{2}$ \\ STIKes Mitra Husada Karanganyar \\ Jl. Brigjen Katamso Barat, Gapura Papahan Indah, Papahan, Kec. Tasikmadu, Kabupaten Karanganyar, \\ Jawa Tengah 57722 \\ *e-mail korespondensi : maisaroh.aini25@gmail.com ${ }^{1}$
}

\begin{abstract}
Abstrak
Sistem Informasi Manajemen Rumah Sakit (SIMRS) merupakan suatu sistem teknologi informasi komunikasi yang memproses dan mengintegrasikan seluruh alur proses pelayanan Rumah Sakit dalam bentuk jaringan koordinasi, pelaporan dan prosedur administrasi. Penelitian ini bertujuan mengetahui faktor yang mempengaruhi keberhasilan implementasi SIMRS. Metode penelitian ini menggunakan metode literature review. Teknik pengambilan data dalam penelitian ini menggunakan data sekunder yang diperoleh dari penelitian yang dilakukan oleh peneliti terdahulu. Hasil penelitian menyebutkan bahwa faktor yang mempengaruhi implementasi SIMRS berdasarkan faktor manusia adalah kepuasan pengguna (user satisfaction) dan penggunaan sistem (system use). Faktor organisasi adalah struktur organisasi, lingkungan organisasi (Environment), dukungan pimpinan, manajemen proyek, dan kondisi fasilitas. Faktor teknologi adalah kualitas sistem (System Quality), kualitas informasi (Information Quality), kualitas layanan (Service Quality) dan vendor support. Upaya yang harus dilakukan untuk meningkatkan keberhasilan implemetasi SIMRS yaitu pelatihan penggunaan sistem, meningkatkan infrastruktur pendukung SIMRS, evaluasi SIMRS dan peningkatan kualitas teknologi sehingga dapat memberikan hasil yang lebih baik serta berhasil mengimplementasikan SIMRS dengan baik dan benar.
\end{abstract}

Kata kunci : : Implementasi SIMRS, Faktor Keberhasilan, Metode HOT-Fit

\begin{abstract}
Hospital Management Information System (SIMRS) is a communication information technology system that processes and integrates the entire flow of hospital service processes in the form of a network of coordination, reporting and administrative procedures. This study aims to determine the factors that influence the successful implementation of SIMRS. This research method uses the literature review method. The data collection technique in this study used secondary data obtained from research conducted by previous researchers. The results of the study stated that the factors that influence the implementation of SIMRS based on human factors are user satisfaction and system use. Organizational factors are organizational structure, organizational environment (Environment), leadership support, project management, and facility conditions. Technological factors are system quality (System Quality), information quality (Information Quality), service quality (Service Quality) and vendor support. Efforts must be made to improve the success of SIMRS implementation, namely training on the use of the system, improving SIMRS supporting infrastructure, evaluating SIMRS and improving technology quality so that it can provide better results and successfully implement SIMRS properly and correctly.
\end{abstract}

Keywords: SIMRS Implementation, Success Factors, HOT-Fit Method

p-ISSN: | e-ISSN: 2807-2596

website: ijhim.stikesmhk.ac.id/index.php/ 
2 | Indonesian Journal of Health Information Management (IJHIM), Vol. 2 No. 2 (2022),

\section{PENDAHULUAN}

\section{Berdasarkan Peraturan Menteri Kesehatan Republik Indonesia nomor} 1171/MENKES/PER/VI/2011 yang menyebutkan bahwa "setiap rumah sakit wajib melaksanakan Sistem Informasi Rumah Sakit" maka rumah sakit yang ada di indonesia mulai menerapkan sistem untuk meningkatkan pelayanan. SIMRS adalah suatu sistem terkomputerisasi yang mampu melakukan pengolahan data secara cepat, akurat, dan menghasilkan sekumpulan informasi yang saling berinteraksi untuk diberikan kepada semua tingkatan manajemen di rumah sakit. Hasil informasi dari data yang telah diolah yaitu berupa laporan, dapat digunakan oleh pengguna dalam mengambil keputusan untuk peningkatan upaya pelayanan kesehatan. SIMRS berfungsi untuk pengendalian mutu pelayanan, pengendalian mutu dan penilaian produktivitas, penyederhanaan pelayanan, analisis manfaat dan perkiraan kebutuhan, penelitian klinis, pendidikan, serta perencanaan dan evaluasi program.

Sistem Informasi Manajemen Rumah Sakit (SIMRS) merupakan suatu sistem teknologi informasi komunikasi yang memproses dan mengintegrasikan seluruh alur proses pelayanan Rumah Sakit dalam bentuk jaringan koordinasi, pelaporan dan prosedur administrasi untuk memperoleh informasi secara tepat dan akurat dan merupakan bagian dari Sistem Informasi Kesehatan.

Terdapat lima komponen yang mendasari implementasi SIMRS yaitu sumber daya manusia (SDM), perangkat keras (hardware), perangkat lunak (software), data, dan jaringan. SDM sebagai pengguna SIMRS merupakan faktor utama dalam penerimaan sebuah teknologi baru. Proses adopsi dalam penerapan SIMRS merupakan bagian perilaku manusia dan menentukan kelancaran penerapan SIMRS. Perangkat teknologi berperan pada tingkat kesulitan atau kemudahan dalam penerapan serta manfaat bagi individu maupun organisasi, sehingga masing-masing komponen dapat menjadi masalah dan menyebabkan gangguan dalam implementasi SIMRS (Suyanto, 2015). Penelitian yang akan dilakukan terhadap SIMRS mengacu pada kerangka kerja HOT-Fit dan merupakan salah satu kerangka teori yang digunakan untuk evaluasi sistem informasi dalam bidang pelayanan kesehatan. Teori HOT-Fit ditujukan pada komponen inti dalam sistem informasi yaitu Human (manusia), Organization (organisasi), Technology (Teknologi) dan kecocokan diantar ketiga komponen tersebut (Yusof et al 2006). Teori HOT-Fit dikemukakan oleh Yusof et al. (2006) di konferensi Internasional Hawaii Sciences System ke-39.

Pelaksanaan SIMRS yang belum berjalan lancar, hal ini disebabkan SIMRS yang diterapkan oleh rumah sakit dianggap kurang diperhatikan pihak terkait dan belum mempersiapkan segala sesuatu yang berkaitan dengan SIMRS dengan baik seperti banyaknya petugas yang belum memahami dan mengerti, ini dikarenakan belum adanya dukungan, pengawasan dan evaluasi dari manajemen serta teknologi yang belum berjalan secara maksimal (Wulandari \& Putra, 2020)

Rumah sakit yang telah menerapkan SIMRS cukup lama, tetapi belum sepenuhnya merasakan manfaatnya oleh stakeholder. Implementasi SIMRS yang kurang baik tentunya akan mempengaruhi mutu pelayanan rumah sakit. Hal tersebut akan mempengaruhi kepuasan pengguna layanan. Faktor yang paling berpengaruh dalam implementasi SIMRS adalah people (manusia) (Igiany, 2019)

Berdasarkan pada jurnal penelitian di atas ditemukan beberapa faktor ketidakberhasilan SIMRS yaitu kepuasaan pengguna, penggunaan sistem, dukungan dari manajemen, dan kualitas teknologi. Sehingga peneliti tertarik untuk melakukan "Studi Literature Review Tentang Analisis Faktor Keberhasilan Implementasi Sistem Informasi Manajemen Rumah Sakit Dengan Metode Hot-Fit”.

\section{METODE PENELITIAN}

Penelitian ini menggunakan desain literature review yaitu penelitian yang mengkaji artikel-artikel ilmiah dengan mengintegrasikan dan menarik kesimpulan tentang faktor keberhasilan implementasi sistem informasi manajemen rumah sakit (SIMRS) dengan metode HOT-Fit.

Data yang digunakan dalam penelitian ini adalah data sekunder yang diperoleh bukan dari pengamatan secara langsung, akan tetapi dari hasil penelitian yang telah dilakukan peneliti terdahulu. Sumber data penelitian didapat berupa artikel atau jurnal yang revelan dengan topic Analisis Faktor Keberhasilan Implementasi Sistem Informasi Manajemen Rumah Sakit Dengan Metode Hot-Fit. Pencarian data tersebut dilakukan dengan menggunakan database Google Scholar.Kata kunci yang digunakan dalam penelitian ini yaitu "Implementasi SIMRS" OR "Faktor Keberhasilan" AND "Metode HOT-Fit". 
HASIL

\begin{tabular}{|c|c|c|c|c|}
\hline$\frac{\text { Author }}{\text { (tahun) }}$ & $\begin{array}{c}\text { Nama jurnal, } \\
\text { Volume, No }\end{array}$ & Judul & Metode & Hasil \\
\hline $\begin{array}{l}\text { Andika } \\
\text { Bayu S, Izza } \\
\text { Muhimah } \\
(2013)\end{array}$ & $\begin{array}{l}\text { Seminar } \\
\text { Nasional } \\
\text { Informatika } \\
\text { Medis } \\
\text { (SNIMed) IV, } \\
\text { p. 78, 2013 }\end{array}$ & $\begin{array}{l}\text { Evaluasi } \\
\text { Faktor } \\
\text { Kesuksesan } \\
\text { Implementasi } \\
\text { Sistem } \\
\text { Informasi } \\
\text { manajemen } \\
\text { Rumah Sakit } \\
\text { di PKU } \\
\text { Muhammadiy } \\
\text { ah Sruweng } \\
\text { dengan } \\
\text { Menggunakan } \\
\text { Metode Hot- } \\
\text { Fit }\end{array}$ & $\begin{array}{l}\text { Studi } \\
\text { Literature }\end{array}$ & $\begin{array}{l}\text { Faktor yang mempengaruhi keberhasilan } \\
\text { penerapan SIMRS adalah } \\
\text { a. Faktor human (manusia) } \\
\text { yaitupenggunaan sistem dan kepuasan } \\
\text { pengguna } \\
\text { b. Faktor organization (organisasi) yaitu } \\
\text { struktur organisasi dan lingkungan } \\
\text { organisasi. } \\
\text { c. Faktor technology (teknologi) yaitu } \\
\text { kualitas sistem, kualitas informasi dan } \\
\text { kualitas layanan. }\end{array}$ \\
\hline $\begin{array}{l}\text { Putra et al., } \\
2020\end{array}$ & $\begin{array}{l}\text { Jurnal Ilmiah } \\
\text { Manusia dan } \\
\text { Kesehatan, } \\
\text { Vol. 1, No. 1 } \\
\text { Januari 2020 } \\
\text { pISSN 2614- } \\
\text { 5073, } \\
\text { eISSN2614- } \\
3151\end{array}$ & $\begin{array}{l}\text { Evaluasi } \\
\text { Sistem } \\
\text { Informasi } \\
\text { Manajemen } \\
\text { Rumah Sakit } \\
\text { (SIMRS) } \\
\text { Dengan } \\
\text { Metode Hot- } \\
\text { Fit Di RSUD } \\
\text { Andi } \\
\text { Makkasau } \\
\text { Kota Pare- } \\
\text { pare }\end{array}$ & $\begin{array}{l}\text { Deskriptif } \\
\text { Kualitatif }\end{array}$ & $\begin{array}{l}\text { Faktor yang mempengaruhi keberhasilan } \\
\text { penerapan SIMRS adalah } \\
\text { a. Faktor human (manusia) menilai dari } \\
\text { sisi penggunaan sistem (system use) } \\
\text { pada frekuensi dan luasnya fungsi } \\
\text { sistem informasi. } \\
\text { b. Faktor organization (organisasi)menilai } \\
\text { dari aspek struktur organisasi dan } \\
\text { lingkungan organisasi terdiri dari tipe, } \\
\text { kultur, politik, hirearki, perencanaan } \\
\text { dan pengendalian sistem, strategi, } \\
\text { manajemen dan komunikasi. } \\
\text { c. Faktor technology (teknologi) menilai } \\
\text { dari kualitas sistem (system quality), } \\
\text { kualitas informasi (information quality) } \\
\text { dan kualitas layanan (service quality). }\end{array}$ \\
\hline $\begin{array}{ll}\text { Abda'u } & \text { et } \\
\text { al., 2018 } & \end{array}$ & $\begin{array}{l}\text { Jurnal Ilmiah } \\
\text { Penelitian dan } \\
\text { Penerapan } \\
\text { Teknologi } \\
\text { Sistem } \\
\text { Informasi, } \\
\text { Vol.2 No.1 } \\
\text { February } 2018 \\
\text { ISSN: 2580- } \\
\text { 409X (Print) / } \\
\text { 2549-6824 } \\
\text { (Online) }\end{array}$ & $\begin{array}{l}\text { Evaluasi } \\
\text { Penerapan } \\
\text { SIMRS } \\
\text { Menggunakan } \\
\text { Metode Hot- } \\
\text { Fit Di RSUD } \\
\text { Dr. Soedirman } \\
\text { Kebumen }\end{array}$ & $\begin{array}{l}\text { Deskriptif } \\
\text { Kuantitatif }\end{array}$ & $\begin{array}{l}\text { Kesuksesan dalam penerapan SIMRS } \\
\text { dipengaruhi oleh } \\
\text { a. Faktor human (manusia)adalah } \\
\text { penggunaan sistem (system use) dan } \\
\text { kepuasan pengguna (user satisfaction). } \\
\text { 1) Dari sisi penggunaan sistem (system } \\
\text { use) contohnya seperti: penggunaan } \\
\text { SIMRS mempermudah proses } \\
\text { pencarian informasi, membantu } \\
\text { pekerjaan sehari-hari dan membantu } \\
\text { dalam pengambilan keputusan. } \\
\text { 2) Dari sisi kepuasan pengguna (user } \\
\text { satisfaction) contohnya seperti puas } \\
\text { terhadap fasilitas dan fitur-fitur pada } \\
\text { SIMRS yang telah berjalan sesuai } \\
\text { kebutuhan, puas terhadap tampilan } \\
\text { SIMRS dan SIMRS mudah } \\
\text { digunakan }\end{array}$ \\
\hline
\end{tabular}




\begin{tabular}{|c|c|c|c|}
\hline $\begin{array}{l}\text { Author } \\
\text { (tahun) }\end{array}$ & $\begin{array}{c}\text { Nama jurnal, } \\
\text { Volume, No }\end{array}$ & Judul & Metode \\
\hline
\end{tabular}

b. Faktor organization (organisasi) adalah Struktur Organisasi, Dukungan Pimpinan, Kondisi Fasilitas.

1) Dari sisi Struktur Organisasi contohnya seperti: SIMRS diterapkan sebagai strategi untuk peningkatan kinerja, SIMRS dapat membantu koordinasi antar unit.

2) Dari sisi Dukungan Pimpinan contohnya seperti: implementasi SIMRS didukung pimpinan/top management, atasan menganjurkan menggunakan SIMRS, menganggap SIMRS penting dan bermanfaat.

3) Dari sisi kondisi fasilitas, contohnya seperti: Instansi menyediakan pelatihan SIMRS, Instansi menyediakan sumber daya, sarana dan prasarana.

c. Faktor technology (teknologi) adalah kualitas sistem (System quality), kualitas informasi (information quality), kualitas layanan (service quality).

1) Dari sisi kualitas sistem contohnya seperti: SIMRS user frendly, SIMRS memiliki hak akses.

2) Dari sisi kualitas informasi contohnya seperti: Informasi yang dihasilkan SIMRS sesuai dengan kenyataan, tepat akurat dan mudah dibaca.

3) Dari kualitas layanan contohnya seperti: Adanya panduan penggunaan SIMRS, Layanan yang cepat dan responsif dari pihak pengembang SIMRS.

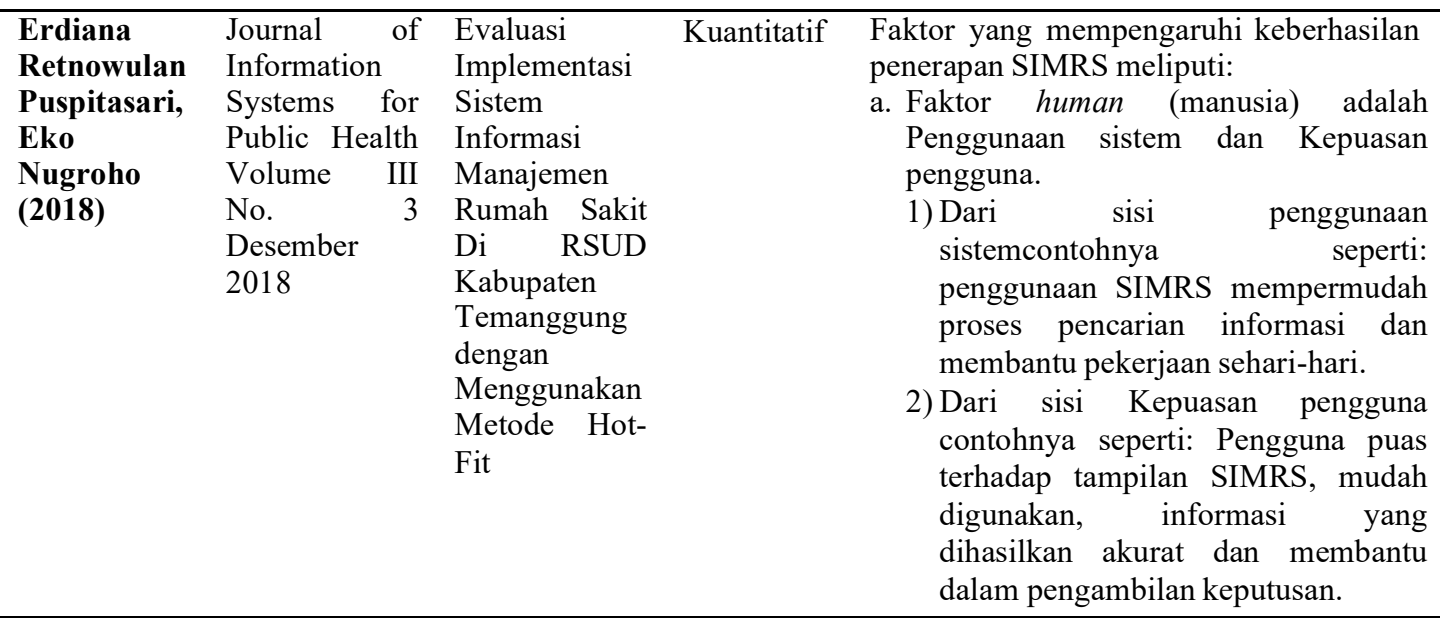




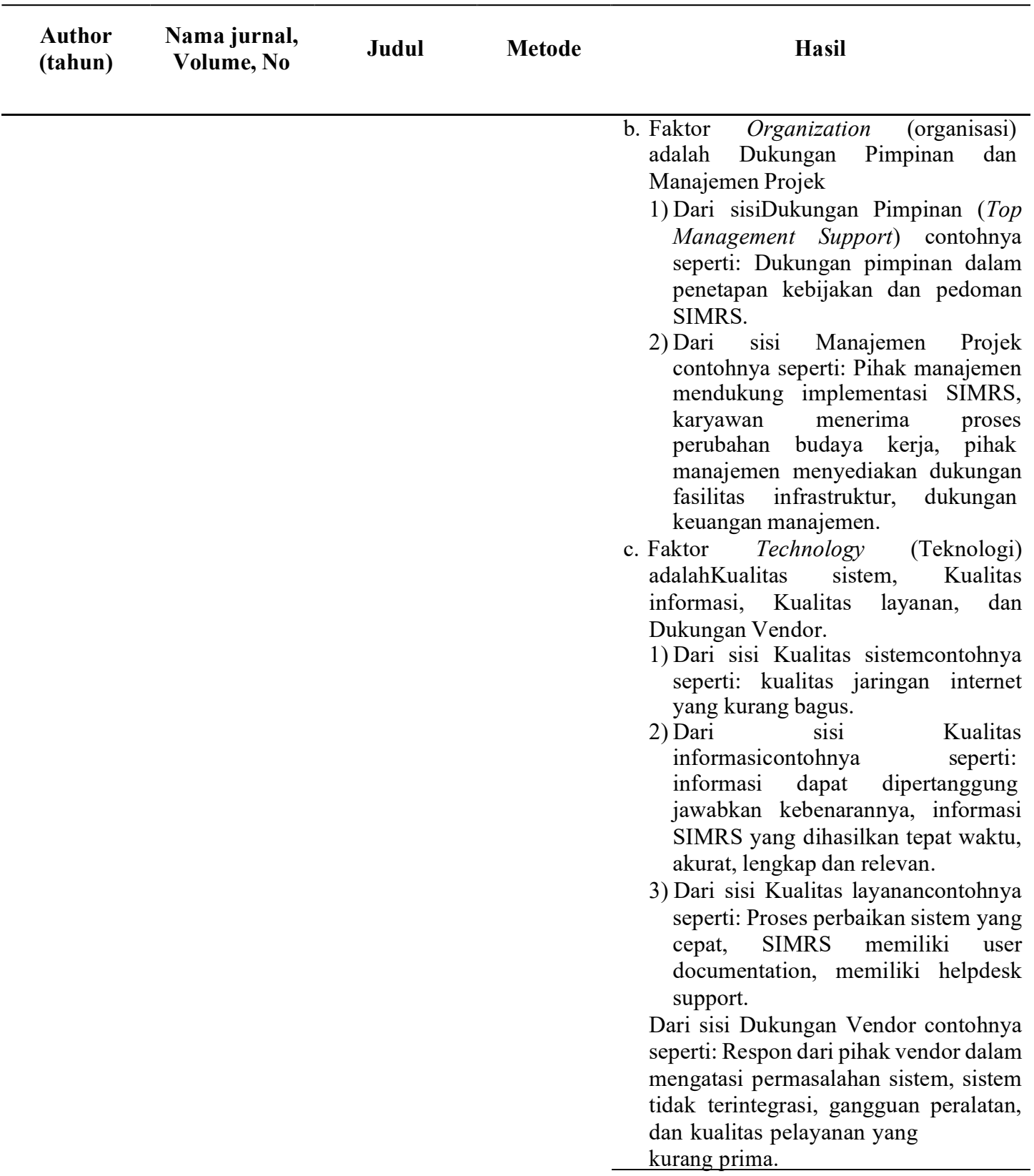

\begin{tabular}{llll}
\hline Andika & Jurnal & Identifikasi & Deskriptif, \\
Bayu & Penelitian Pers & Faktor-Faktor & Kuantitatif \\
Saputra & dan & Keberhasilan & \\
(2016) & Komunikasi & Implementasi & \\
& Pembangunan & Sistem & \\
& Vol. 19 No.3 & Informasi & \\
& Februari & Manajemen & \\
& 2016:135-148 & Rumah Sakit
\end{tabular}

Faktor yang mempengaruhi keberhasilan penerapan SIMRS meliputi:

a. Faktor Human (Manusia) adalah Penggunaan sistem dan Kepuasan pengguna.

1) Dari sisi Penggunaan sistem (system use) contohnya seperti: pengaruh penggunaan sistem informasi terhadap efek pekerjaan, efisien dan efektifitas, menurunkan tingkat kesalahan, pengendalian pengeluaraan dan biaya.

2) Dari sisi Kepuasan pengguna (User satisfaction) contohnya seperti: semakin efektif dan efisien pelayanan RS.

p-ISSN: | e-ISSN: 2807-2596

website: ijhim.stikesmhk.ac.id/index.php/ 


\begin{tabular}{|c|c|c|c|c|}
\hline $\begin{array}{l}\text { Author } \\
\text { (tahun) }\end{array}$ & $\begin{array}{c}\text { Nama jurnal, } \\
\text { Volume, No }\end{array}$ & Judul & Metode & Hasil \\
\hline & & & & $\begin{array}{l}\text { b. Faktor Organization (organisasi) } \\
\text { adalah Structure dan Environment. } \\
\text { 1) Dari sisi Struktur organisasi } \\
\text { contohnya seperti dukungan } \\
\text { pemimpin, kerja tim dan komunikasi } \\
\text { efektif dengan melibatkan peran dan } \\
\text { kemampuan petugas. } \\
\text { 2) Dari sisi Lingkungan (Enviroment) } \\
\text { contohnya seperti: dukungan dari top } \\
\text { manajemen dan dukungan staf. } \\
\text { c. Faktor Technology (Teknologi) adalah } \\
\text { Kualitas sistem, Kualitas informasi, dan } \\
\text { Kualitas layanan. } \\
\text { 1) Dari sisi Kualitas sistem (system } \\
\text { quality) contohnya seperti: sistem } \\
\text { informasi dinilai dari kemudahan } \\
\text { penggunaan, kemudahan dipelajari, } \\
\text { response time, usefulness, } \\
\text { ketersedian, fleksibelitas, dan } \\
\text { keterkaitan fitur dalam sistem. } \\
\text { 2) Dari sisi Kualitas informasi } \\
\text { (information quality) contohnya } \\
\text { seperti: kualitas informasi antara lain } \\
\text { kelengkapan, keakuratan, ketepatan } \\
\text { waktu, ketersediaan, relevansi, } \\
\text { konsistensi dan data entry. } \\
\text { 3) Dari sisi Kualitas layanan (service } \\
\text { quality) contohnya seperti: respon } \\
\text { yang tinggi dari vendor. }\end{array}$ \\
\hline
\end{tabular}

\section{PEMBAHASAN}

Faktor Manusia (Human) yang mempengaruhi keberhasilan implementasi SIMRS

\section{Kepuasan pengguna (user satisfaction)}

Pelaksanakan SIMRS memudahkan dalam membantu mengelolah informasi. Pada awal menggunakan SIMRS yang dirasakan petugas adalah adanya kesulitan, tapi setelah mengikuti pelatihan menggunakan SIMRS petugas dapat menerima dan merasa puas dengan adanya SIMRS. Ini dikarenakan SIMRS sangat membantu partisipan dalam bekerja, efisien terhadap waktu, dan memudahkan dalam pencarian data pasien.

Kepuasan pengguna dalam implementasi SIMRS meliputi: puas terhadap tampilan aplikasi, kemudahan penggunaan sistem, fasilitas dan fiturfitur yang ada pada SIMRS sudah sesuai dengan kebutuhan, informasi yang dihasilkan oleh sistem akurat dan dapat membantu dalam proses pengambilan keputusan.

\section{Penggunaan sistem (system use)}

Penggunaan SIMRS pada dasarnya membantu dalam pelayanan di rumah sakit. Karena sistem ini sering digunakan dalam kegiatan sehari-hari sebagai tugas rutin, hal ini membuat pengguna menjadi terbiasa dengan sistem ini sehingga mudah dalam penggunaanya.

Penggunaan sistem (system use) berhubungan dengan siapa yang menggunakan (who use it), tingkat penggunanya (level of user), pelatihan, pengetahuan, harapan dan sikap menerima (acceptance) atau menolak (resistance) sistem. Dalam mendukung penggunaan sistem perlu adanya pelatihan penggunaan, konsul dan bimbingan dari pihak rumah sakit.

Penggunaan sistem (system use) dalam implementasi SIMRS meliputi: mempermudah proses pencarian informasi, SIMRS sangat membantu pekerjaan sehari-hari dalam proses pelayanan rumah sakit. Untuk mencapai net benefit yang diinginkan, rumah sakit perlu meningkatkan kualitas sistem tersebut. 
Faktor Organisasi (Organization) yang mempengaruhi keberhasilan implementasi SIMRS

\section{Struktur organisasi (Structure)}

Struktur organisasi meliputi tipe, kultur, politik, hirarki, perencanaan dan pengendalian sistem, strategi, manajemen dan komunikasi. Struktur organisasi mencerminkan keadaan instansi, budaya, politik, hirarki, autonomi, perencanaan dan sistem control, strategi, manajemen, kepemimpinan dan komunikasi.

Struktur organisasi pada implementasi SIMRSmeliputi: SIMRS yang diterapkan sebagai strategi untuk peningkatan kinerja, SIMRS membantu koordinasi antar unit dengan baik, SIMRS dapat digunakan sesuai dengan fungsi dan tugas dalam organisasi dan pihak organisasi menyediakan dukungan fasilitas seperti dukungan infrastruktur untuk SIMRS.

\section{Lingkungan organisasi (Environment)}

Lingkungan organisasi adalah lingkungan diluar dari organisasi seperti, politik, kebijakan pemerintah, sumber keuangan (pemilik modal), lokasi, kompetisi, hubungan antar instansi, populasi yang dilayani dan komunikasi. Keberhasilan implementasi SIMRS dari sisi lingkungan organisasi dapat dicapai melalui strategi dan manajemen seperti dukungan pemimpin, kerja tim, dan komunikasi efektif yang dibentuk dengan melibatkan peran dan kemampuan karyawan.

Lingkungan organisasi pada implementasi SIMRS meliputi: lingkungan yang menjadi sumber pembiayaan, pemerintahan, politik, kompetisi, hubungan interorganisasional dan komunikasi pada implementasi SIMRS.

\section{Dukungan Pimpinan (Top Management Support)}

Dukungan pimpinan dalam bentuk komitmen pemimpin pada SIMRS masih belum maksimal. Pimpinan belum menetapkan kebijakan dan pedoman penggunaan SIMRS.

Jajaran manajemen puncak ini dapat dipelajari profil dan visi misi karyawan serta jajaran manajemen menengah dari suatu instansi, sehingga penguatan di manajemen puncak akan berpengaruh terhadap keberhasilan adopsi TI.

Dukungan pimpinan dalam implemetasi SIMRS berupa: implementasi SIMRS didukung oleh pimpinan/top management, pimpinan menganjurkan untuk menggunakan SIMRS, dan SIMRS dianggap penting dan bermanfaat pada rumah sakit.

\section{Manajemen proyek (Project Management)}

Manajemen proyek menunjukkan bahwa pihak manajemen mendukung implementasi SIMRS, karyawan menerima proses perubahan budaya kerja dari pencatatan kertas ke sistem SIMRS dan pihak manajemen menyediakan dukungan fasilitas infrastruktur umtuk mendukung implementasi SIMRS.

Penerapan SIMRS mendapat dukungan keuangan dari manajemen. Staf medis yang aktif menggunakan SIMRS merupakan salah satu faktor yang mendorong adopsi sistem informasi. Kekompakan staf, dukungan antar rekan kerja, penggunaan SIMRS secara teratur merupakan faktor pendorong penggunaan SIMRS.

\section{Kondisi Fasilitas}

Kondisi fasilitas ini seperti Instansi menyediakan sumber daya, sarana dan prasarana (hardware, software, infrastruktur jaringan, pemeliharaan dan dukungan teknis) yang mendukung penggunaan SIMRS, Instansi menyediakan pelatihan menggunakan SIMRS, dan terdapat petugas yang bertanggung jawab serta memberikan bantuan jika terjadi masalah dengan SIMRS.

Faktor Teknologi (Technology) yang mempengaruhi keberhasilan implementasi SIMRS

\section{Kualitas Sistem (System Quality)}

Kualitas sistem akan memuaskan penggunanya dengan adanya kemudahaan sistem agar memberikan manfaat optimal bagi para pengguna dengan lebih meningkatkan penggunaan SIMRS di rumah sakit.

Kualitas sistem dalam sistem informasi dapat dinilai dari kemudahan penggunaan (easy of use), kemudahan untuk dipelajari (easy of learning), response time, usefulness, ketersediaan, fleksibilitas, dan sekuritas serta menyangkut keterkaitan fitur dalam sistem termasuk performa sistem dan user interface pada SIMRS.

\section{Kualitas Informasi (Information Quality)}

Kriteria dari kualitas informasi adalah kelengkapan, ketepatan, kemudahan pembacaan, tepat waktu, ketersediaan, relevansi, konsistensi, tahan uji, metode input data, dan kualitas. Kualitas suatu informasi tergantung dari tiga hal yaitu:

1) Akurat, informasi harus bebas dari kesalahan dan harus jelas mencerminkan maksudnya.

2) Tepat pada waktunya, informasi yang dating ke penerima tidak boleh terlambat. Informasi yang usang tidak ada nilainya lagi. Karena informasi menjadi landasan dalam pengambilan keputusan. 
3) Relevan, informasi tersebut mempunyai manfaat untuk pemakainya.

Kualitas informasi pada implementasi SIMRS meliputi: informasi yang dapat dipertanggung jawabkan kebenarannya, informasi yang dihasilkan tepat waktu, akurat, lengkap, relevan dan mudah dibaca.

\section{Kualitas Layanan (Service Quality)}

Pengukuran kualitas layanan secara keseluruhan dari dukungan penyedia jasa sistem atau teknologi. Kriteria yang diukur adalah kecepatan respons, jaminann layanan, empati dan penanganan layanan. Kepuasan pengguna disebabkan karena layanan vendor yang cepat saat dibutuhkan, vendor memberikan jaminan kualitas dan layanan terhadap penggunaan SIMRS serta mampu menyelesaikan permasalahan.

Kualitas layanan pada implementasi SIMRS meliputi: Adanya panduan penggunaan SIMRS, Layanan yang cepat dan responsif pada saat jam-jam pelayanan serta respon cepat dari pihak pengembang, Proses perbaikan sistem yang cepat, SIMRS mempunyai user documentation dan memiliki helpdesk support.

\section{Dukungan Vendor (Vendor Support)}

Layanan vendor dibagian tertentu dinilai kurang cepat, karena keterbatasan personil vendor. Berdasarkan hal tersebut dapat menunjukkan ketidakpuasan pengguna disebabkan karena layanan vendor yang kurang cepat responnya saat dibutuhkan, tidak tersedianya helpdesk, vendor belum memberikan jaminan kualitas dan layanan terhadap penggunaan SIMRS serta belum mampu menyelesaikan permasalahan yang mungkin timbul dalam penggunaan SIMRS.

Dukungan vendor pada implementasi SIMRS meliputi: Respon dari pihak vendor dalam mengatasi permasalahan sistem (sistem tidak terintegrasi), gangguan peralatan, dan layanan yang kurang prima.

\section{SIMPULAN}

Faktor yang mempengaruhi keberhasilan implementasi SIMRS dengan menggunakan metode HOT-Fit berdasarkan manusia (Human) adalah kepuasan pengguna (user satisfaction) dan penggunaan sistem (system use). Tingkat kepuasan pengguna berpengaruh secara langsung terhadap penggunaan sistem, sehingga sistem informasi (SIMRS) akan sering digunakan. Penggunaan sistem mempermudah proses pencarian informasi dan membantu proses pelayanan rumah sakit bagi petugas. Penggunaan sistem yang berkualitas dapat mencapai manfaat (net-benefit) yang diinginkan rumah sakit. Faktor yang mempengaruhi keberhasilan implementasi SIMRS dengan menggunakan metode HOT-Fit berdasarkan organisasi (Organization) adalah struktur organisasi, lingkungan organisasi (Environment), dukungan pimpinan, manajemen proyek, dan kondisi fasilitas. Faktor yang mempengaruhi keberhasilan implementasi SIMRS dengan menggunakan metode HOT-Fit berdasarkan teknologi (Technology) adalah kualitas sistem (System Quality), kualitas informasi (Information Quality), kualitas layanan (Service Quality) dan dukungan vendor (vendor support).

\section{SARAN}

Dari faktor manusia (human) sebaiknya perlu adanya peningkatan hubungan antara teknologi dan pengguna (human) agar penggunaan SIMRS dapat lebih ditingkatkan guna mendukung pelayanan yang prima. Dengan adanya pelatihan penggunaan sistem.

Dari faktor organisasi (organization) sebaiknya lebih memperhatikan infrastruktur pendukung SIMRS karena tanpa dukungan dari manajemen akan banyak mucul permasalahan yang dapat mempengaruhi penerapan SIMRS.

Dari faktor teknologi (technology) sebaiknya dilakukan evaluasi SIMRS secara periodik guna mengetahui kekurangan SIMRS dalam memenuhi kebutuhan pengguna, serta sebaiknya ada peningkatan dan perbaikan kualitas teknologi agar pengguna terbiasa, lebih mudah mengoperasikan SIMRS sehingga bisa lebih meningkatkan kepuasan pengguna. Dan sebaiknya pihak vendor lebih meningkatkan kehandalan sistem, juga memberikan respon yang cepat jika terjadi masalah pada sistem.

\section{DAFTAR RUJUKAN}

Abda'u, P. D., Winarno W., W., \& Henderi (2018). Evaluasi Penerapan SIMRS Menggunakan Metode Hot-Fit Di RSUD Dr. Soedirman Kebumen. Jurnal Ilmiah Penelitian dan Penerapan Teknologi Sistem Informasi, 2 (1),46-56.

https://ojs.unpkediri.ac.id/index.php/intensif/ article/view/11817 Diakses pada 15 Desember 2020

Depkes RI. (2006). Pedoman Penyelenggaraan dan Prosedur Rekam Medis Rumah Sakit. Jakarta: Departemen Kesehatan Republik Indonesia.

Yusof, M. M., R. J. Paul, and L. K. Stergioulas. (2006). Towards a Framework for Health Information Systems Evaluation. in Hawaii International Conference on System Sceinces. 
39 (110).

https://www.researchgate.net/publication/421

$\underline{6197}$ Diakses pada 10 Januari 2021

Menkes RI. 2011. Peraturan Menteri Kesehatan Republik Indonesia No. 1171/MENKES/Per/VI/2011 Tentang Sistem Informasi Rumah Sakit. Jakarta: Departemen Kesehatan Republik Indonesia.

Putra, A. D., Dangnga, M. S., \& Majid M. (2020). Evaluasi Sistem Informasi Manajemen Rumah Sakit (SIMRS) Dengan Metode HOT FIT Di RSUD Andi Makkasau Kota Parepare. Jurnal Ilmiah Manusia Dan Kesehatan, 1 (1), 61-68.

https://jurnal.umpar.ac.id/index.php/makes/ar ticle/view/294 Diakses pada 15 Desember 2020

Retnowulandari, P. E., Nugroho E. (2018). Evaluasi Implementasi Sistem Informasi Manajemen Rumah Sakit di RSUD Kabupaten Temanggung dengan Menggunakan Metode Hot-Fit. Journal of Information Systems for Public Health3 (3), 63-77. https://jurnal.ugm.ac.id/jisph/article/view/375 $\underline{62}$ Diakses pada 15 Desember 2020
Saputra, A. B. (2016). Identifikasi Faktor-Faktor Keberhasilan Implementasi Sistem Informasi Manajemen Rumah Sakit. Universitas Islam Indonesia. Yogyakarta. Indonesia. Jurnal Penelitian Pers dan Komunikasi Pembangunan, 19 (3), 135-148. https://jurnalp2kp.id/index.php/jp2kp/article/view/33 Diakses pada 15 Desember 2020

Saputra, A. B., Muhimmah I. (2013). Evaluasi Faktor-Faktor Kesuksesan Implementasi Sistem Informasi manajemen Rumah Sakit di PKU Muhammadiyah Sruweng dengan Menggunakan Metode Hot-Fit. Seminar Nasional Informatika Medis (SNIMed) 4, 7886.

https://journal.uii.ac.id/snimed/article/view/4 $\underline{250}$ Diakses pada 15 Desember 2020

Suyanto, Hidayat Taufiq, I. (2015). Faktor Penghambat Implementasi Sistem Informasi Manajemen Rumah Sakit di RSUD Blambangan Banyuwangi. Jurnal Kedokteran Brawijaya. https://jkb.ub.ac.id/index.php/jkb/article/view $\underline{1966}$
p-ISSN: | e-ISSN: 2807-2596

website: ijhim.stikesmhk.ac.id/index.php/ 